\section{A Small Polypoid Lesion in the Lower Common Bile Duct: a Case Study}

Benign small polypoid lesions are very rare in the common bile duct. We describe here a patient with concomitant gallstones. Two similar small lesions have been previously reported $(1,2)$.

A 74-year-old Japanese man presented with obstructive jaundice which improved spontaneously. Endoscopic retrograde cholangiopancreatography revealed a small filling defect, $3 \mathrm{~mm}$ in diameter, in the lower common bile duct (Figure 1). There was no abnormality of the pancreatic duct. Ultrasonographically, the gallbladder could not be identified, but an acoustic shadow was recognized, suggesting a gallbladder filled with stones. At laparotomy, cholelithiasis was confirmed and cholecystectomy was performed. The gallbladder was atrophic and contained multiple small stones. An intraoperative cholangiogram was done, showing a small filling defect in the lower part or the intrapancreatic bile duct, as shown on the preoperatively performed cholangiogram. A choledochoscopic examination revealed a small polypoid lesion in the lower common duct (Figure 2). A sufficiently large biopsy specimen for an intraoperative histological examination showed microscopically an inflammatory polypoid lesion consisting of glands and fibrous stromal tissue, with mild lymphoid infiltration. There were no atypical or mitotic epithelial cells. We therefore performed a sideto-side choledochojejunostomy (Roux-en-Y) in addition to the cholecystectomy.

Benign lesions in the common bile duct reported so far have been said to recur occasionally after local excision. However, almost all the recurrent cases have been single polypoid adenomas, or single /multiple papillomas involving some parts of the extrahepatic ductal system (3). The histological findings in our case were different from these cases. A year and three months after the operation, the patient is now healthy and free of fever, jaundice, and any abdominal symptoms.

\section{References}

I Ro RJ: Extrahepatic obstructive jaundice due to inflammatory polyp of the common bile duct. Postrgrad. Med. J. 1975; 58: 259-260.

2 Shepherd HA, Laidlow AP, Ross AP, et al.: Extrahepatic biliary obstruction by a common bile duct inflammatory polyp in association with a gallstone, and treatment by endoscopic sphincterotomy. Endoscopy 1986: 18: 66-88.

3 Burhans R. Myers RT: Benign neoplasms of the extraheptic biliary ducts. Am. Surg. 1971; 37: 161-166.

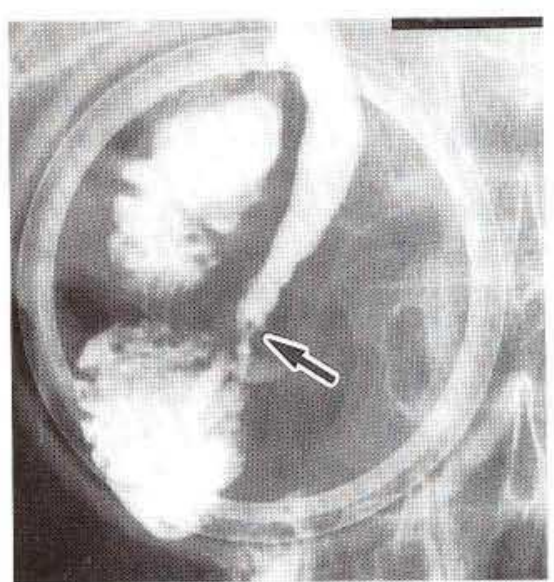

Figure 1:

ERCP demonstrating a small elevated lesion, $3 \mathrm{~mm}$ in diameter, in the lower common bile duct (arrow).

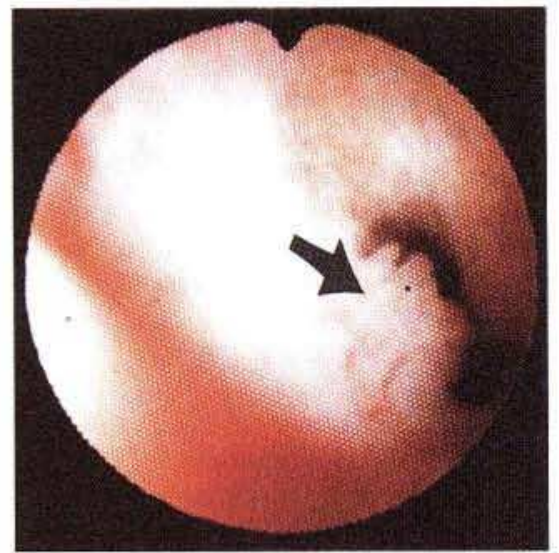

Figure 2:

Choledochoscopic examination revealed a small polypoid lesion in the lower common duct (arrow).

T. Ezaki', T. Okamura ', Y. Yoshida', M. Kitamura ${ }^{2}$, A. Furuta ${ }^{3}$, J. Haratake ${ }^{3}, T$. Shirakusa '

'Second Department of Surgery, School of Medicine. University of Occupational and Environmental Health, Kitakyushu, Japan;

${ }^{2}$ Department of Surgery, Munakata Ishi-Kai Hospital, Munakata, Japan; and ${ }^{3}$ Department of Pathology and Oncology, School of Medicine, University of Occupational and Environmental Health. Kitakyushu 807, Japan 